\title{
AMENDMENTS
}

\section{Author Correction: Higher-order epistasis shapes the fitness landscape of a xenobiotic-degrading enzyme}

Gloria Yang (D), Dave W. Anderson, Florian Baier, Elias Dohmen (D), Nansook Hong, Paul D. Carr,

Shina Caroline Lynn Kamerlin, Colin J. Jackson (D), Erich Bornberg-Bauer (D) and Nobuhiko Tokuriki (D)

Correction to Nature Chemical Biology https://doi.org/10.1038/s41589-019-0386-3, published online 21 October 2019

In the version of this article originally published, some values for AncDHCH3 and BbDHCH in Fig. 1d and Supplementary Table 3 were incorrect. The original and corrected images of Fig. $1 \mathrm{~d}$ are shown here. The errors have been corrected in the HTML and PDF versions of the paper and in the Supplementary Information file.

Original

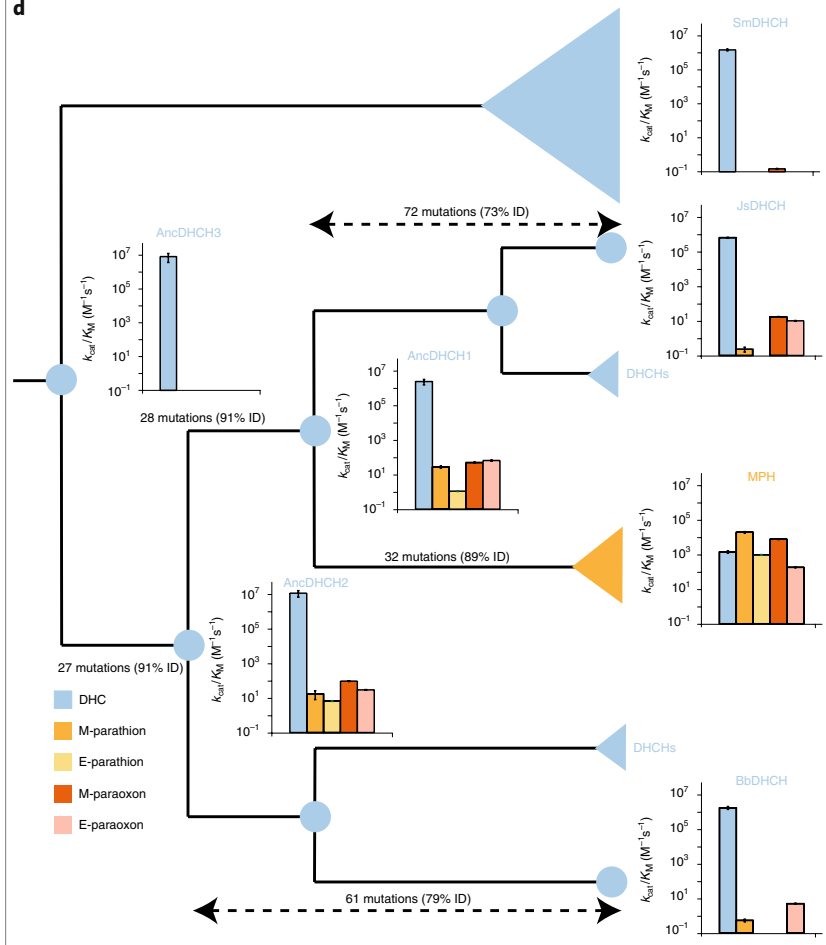

Corrected

d

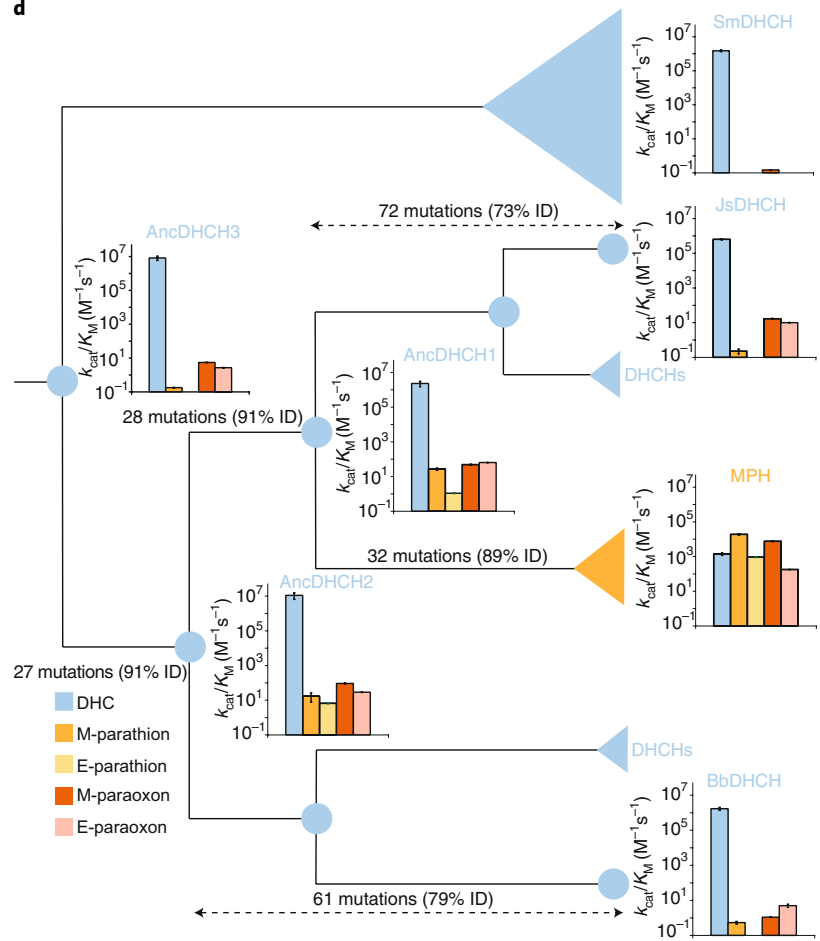

Fig. 1| Original and Corrected.

Published online: 12 June 2020

https://doi.org/10.1038/s41589-020-0588-8

(C) The Author(s), under exclusive licence to Springer Nature America, Inc. 2020 